\title{
Women doctors' perceptions of gender issues in their workplace: Valuable comments from their interviews in a Japanese region
}

\author{
Manabu Murakami ${ }^{1}$, Hidenobu Kawabata ${ }^{2}$, Megumi Kawabata $^{2}$, Masaji Maezawa $^{2}$
}

\begin{abstract}
The number of women doctors is increasing annually in Japan as well as all over the world. The $M$ shaped distribution of their career path is infamous. Preventing the continuous turnover of women doctors and promoting reinstatement could be a key issue. The aim of this study was to clarify the perceptions of gender issues women doctors have regarding their workplace in a Japanese region. We interviewed nine women affiliated with "Hokkaido Medical Women's Association," a regional society of women doctors in Japan. Semi-structured interviews lasting 60 minutes took place. The main topics were what they considered to be gender issues in their clinical practice. All interviews were transcribed in verbatim, and the scripts were analyzed, then repeated themes were identified. Nine themes emerged and were classified into three patterns. (A) The women doctors' own problems: 1) anxiety about future life events, 2) work life balance, 3 ) fear of falling behind and losing up-to-date knowledge and skills. (B) Requirements for mentors or family support: 4) shortage of women doctors as role models, 5) spousal or other relatives' lack of understanding. (C) Institutional or environmental issues: 6) heavy workload in their practice, 7) lack of a support system for raising their children, 8) lack of a system for returning to work, 9) "glass ceiling" issues. These themes were in line with overseas studies which have reported identifiable obstacles for women in medicine. Institutional or environmental support systems rather than personal problems need to be improved above all to rectify the situation.
\end{abstract}

\section{Background}

The rate of qualification of women doctors is increasing annually in Australia, Canada, the United Kingdom and the United States as well as all over the world. For example, In the United Kingdom, it was reported that $25 \%$ of all hospital consultants and $39 \%$ of general practitioners were female in 2003 , while $17 \%$ of hospital consultants were female, as were $29 \%$ of general practitioners in 1993 (Department of Health, 2004; Kilminster et al., 2007).

\footnotetext{
${ }^{1}$ Department of Forensic Medicine, Graduate School of Medicine, Hokkaido University, Hokkaido, Japan

${ }^{2}$ Department of Medical Statistics and Healthcare Systems Research, Graduate School of Medicine, Hokkaido University, Hokkaido, Japan

Corresponding author:

Dr Manabu Murakami

Department of Forensic Medicine, Graduate School of

Medicine, Hokkaido University

North 15 West 7 Kita-ku, Sapporo,

Hokkaido 060-8638 Japan

E-mail: mmanabu@med.hokudai.ac.jp
}

Like other developed countries, the number of women doctors is increasing in Japan, and accounted for approximately $16.4 \%$ of the total number of doctors in the total number of qualified physicians in 2006. However, many researchers emphasize that women doctors are still a minority in high ranking positions in the field of medicine (Reed \& BuddebergFischer, 2001) The M shaped distribution of their career, which means many in the early stage, a decline in the middle stage, and increase again in the later stage, has been well known (Allen, 2005), and even if women doctors hope to return to work, they are often unsuccessful.

Prior studies have suggested that many identifiable impediments still exist, for example, domestic responsibilities or problems, male discrimination in hiring, and structured inflexibilities in the working environment (Kilminster et al., 2007; Reed \& Buddeberg-Fischer, 2001). There is also much discussion about women in medicine or the relationship between women's life stages and 
health in Japan. For example, one of Japan's leading researchers in this field, Prof. Takeda reported "How Concepts of Life Stage Help Your Practice" in the Journal of the Japan Medical Association (Takeda, 2009). Notwithstanding, to our knowledge, few structured research type interview surveys about the problems of women doctors exist in Japan, although many questionnaire surveys have been undertaken. To solve this problem, we adopted the methodology of qualitative interview survey, which was said to be effective for clarifying in depth perception of human thoughts and behaviours (Holloway \& Wheeler, 2000; Ohman, 2005).

The aim of this study was to obtain perceptions of gender issues from women doctors themselves, i.e. to collect women doctors' real opinions about their actual workplace. In some specialties like general internal medicine, preventing women from leaving their clinical practice might be one solution to the shortage of physicians, discussion about which has been abundant recently.

\section{Methods}

We used qualitative research methods with semi-structuredinterviews. Women doctors who belonged to the group of Hokkaido Medical Women's Association, a regional society of women doctors in Japan, were interviewed as a representative sample of actively practicing physicians. We used the snowball sampling method, which is used when researchers do not know who should be chosen, and hope to utilize the network of personal relations amid the initial informant and others (Holloway \& Wheeler, 2000; Ohman, 2005).

Each interview lasted for 45 to 60 minutes, and was recorded in a quiet room in the doctor's office. All participants agreed with the research with both oral and written informed consent. The main interview topics were about what career obstacles women physicians face. An interview guide was created, referring to the prior study (Kilminster et al., 2007; Reed \& Buddeberg-Fischer, 2001): 1.Interviewees' demographic data, 2. Life event issues (for example: "How do you perceive your marriage, childbearing, and caring for your children?") 3 . Work life balance issues (for example: "Do you and your husband share the household chores?") 4. Support system for their work (for example: "Do you have any chance to make use of a day care centre or reinstatement program?") 5. Career ladder (for example: "Do you have any career objectives?").

All interview data were transcribed verbatim and identified and repeated themes concerning their perceptions of gender issue in their workplace were extracted. In more concrete terms, first of all "a meaning unit," or a condensation of words or sentences were labeled. Secondly, "categories," grouped contents sharing common features and being mutually exclusive and exhaustive were generated. Finally, "themes" linking underlying latent meaning in the categories were extrapolated (Holloway \& Wheeler, 2000; Ohman, 2005).

Interviews and analyses took place concurrently by two independent researchers (MuM and HK), and the results were checked by the third author (MK) from a female doctor's actual and practical point of view. Next, the senior researcher (MaM), as supervisor, checked the results. Finally, all of the authors approved the revised themes.

\section{Results}

We interviewed nine women doctors (mean age 45 years old, Table1.) and nine themes divided into three types emerged.

Table1: Characteristics of the Participants

\begin{tabular}{cccc}
\hline No. & Age & Specialty & Years of career \\
\hline 1 & 38 & Pulmonary Medicine & 10 \\
2 & 40 & General Medicine & 15 \\
3 & 44 & Orthopedics & 20 \\
4 & 45 & Pulmonary Medicine & 21 \\
5 & 45 & General Medicine & 21 \\
6 & 46 & Otolaryngology & 21 \\
7 & 47 & Obstetrics and Gynecology & 21 \\
8 & 48 & General Medicine & 22 \\
9 & 48 & Otolaryngology & 22 \\
\hline
\end{tabular}


(A) Women doctors' own problems

Some women doctors experienced anxiety about future life events. They insisted they felt vaguely insecure about future events like marriage, pregnancy, childbirth and raising their children.

"I am enthusiastic about marriage, and want babies, but if I got married, I would not be able to keep my job now."

Other women insisted the problem was work life balance. Their opinions were divided. While some doctors gave their work priority, others thought their families were more important than their practice. One physician changed her policy after the birth of her second child.

"My work had come before my family when raising my first child, but, with the second, I felt what a waste to overlook the growth of my cute kid."

Additionally, women doctors described fear of falling behind with up-to-date knowledge and skills. If they quit their job when they were inexperienced, they felt worried they could not catch up with colleagues in the future.

"When I was at home for half a year, I hoped to work. My work schedule was no longer as tight as before, and I gradually felt uneasy."

\section{(B) Requirements for mentors' or family support}

One participant suggested spousal or other relatives' lack of understanding as the main issue. She insisted that the cooperation of a warm hearted husband was necessary.

"My husband does our housework, takes care of our children, takes children to and from school, and goes to school on parent's visiting day."

Another physician pointed out the shortage of women doctor role models, who can support and advise her about the career. She was disappointed at the present situation where few good women mentors or role models existed and the number of female faculty around her was limited.

"I saw a female doctor working very hard with one thing or another in a certain department. I was glad to see even women could become such an excellent physician. But there are very few doctors like her."

\section{(C) Institutional or environmental issues}

Some women doctors indicated they had a heavy workload in their practice. They stated that the working environment was becoming more severe recently, even though it applied to male doctors, too. They could not leave their work even temporarily due to the way their colleagues looked at them. Due to the worsening shortage of doctors in Japan, especially in rural areas, many doctors feel they may be placing extra burden on their colleagues by going home earlier. In addition, with the strong seniority system in JapanSempai (senior)-Kohai (junior)- junior doctors may feel unable to leave their workplace before their seniors.

"Not only in the case of women, but... I hope physicians will someday be guaranteed at least a daily life as human beings."

Others mentioned the lack of support systems for raising their children. There are many parents waiting to send their children to daycare centres. Women doctors are considered to be rich, so are given low priority as candidates.

"I'd appreciate if working medical staff were given priority."

They also stressed the lack of a system for returning to work.

"The women doctors' network remains only in name. Not so many female doctors are willing to register and keep working."

Finally, they commented on the problem of the glass ceiling or discrimination. They recognized that inequality in opportunities for promotion and disproportionate salaries still remain in Japanese medical society. They proposed women doctors should be more enthusiastic about their promotion.

"I was reluctant to be treated as the clerk who serves the tea. Not so many women choose to go out and become active members of society."

\section{Discussion}

Our interviews clarify the real voice of women physicians who were engaging in the forefront of their practices, which is the novelty and importance of this study. It revealed difficulties in the current practice of women doctors, which were similar to those identified in studies overseas. For example, researchers in 
Japan and Western countries have found that female physicians are inclined to report lower confidence levels regarding their clinical competence or academic level compared to males (Nomura \& Gohchi, 2012; Bakken et al., 2003). Several previous studies have shown that the solution requires a strong foundation and institution-led or government initiatives, which are not limited to individual or isolated efforts (Reed \& Buddeberg-Fischer, 2001; Allen, 2004; Kilminster et al., 2007;). Developing systematic action plans and programs to assist female doctors in promoting their career ladder are necessary. In addition, we propose that it is necessary to cooperate and exchange opinions with organizations concerned and societies for women doctors, because solving these problems alone without institutional aid would be difficult (Kilminster et al., 2007; Reed \& Buddeberg-Fischer, 2001).

In this research, we extracted nine themes divided into three types. The strength of this study was that it focused on the actual opinion of women physicians working at forefront of Japanese medicine, and these opinions are invaluable for improving the working environment of future women doctors. However, one limitation to our pilot interview survey might be that it was carried out in one particular female physicians' group and subject to bias. According to one prior report (Mason, 2010), a suitable sample size seems to be approximately 20 to 30 to achieve theoretical sampling, though qualitative research is flexible and we cannot decide the number of interviewees beforehand. Therefore, further complementary interviews are required to validate the research results. In the interviews, we must clarify: 1) why some women doctors hesitate to return to their work and others succeed to return, and 2) how their partners or male physicians around them think about the women doctors' support, by adopting appropriate theoretical sampling.

\section{Conclusion}

In summary, we report nine themes that emerged from the opinions of women physicians working in the forefront of Japanese medicine. Regarding female economic participation, a large gender gap between men and women still exists in Japan. Japan was ranked 100th out of 135 countries which is the lowest rank among all OECD countries (Nomura \& Gohchi, 2012). Especially in the field of medicine, a tendency for such disparities to exist is more evident.
Taking immediate systematic action by institutional or governmental initiatives is necessary to settle this matter and break through the "glass ceiling."

Acknowledgement: Part of this paper was presented at the conference of the Japan Society for Medical Education, Tokyo, Japan on July 30, 2010.

Ethical approval: Formal ethical approval was obtained from The University Ethics Committee at Hokkaido University, Graduate School of Medicine.

\section{References}

Allen, I. (2005) Women doctors and their careers: what now? BMJ, 331, 7516, pp. 569-572.

Bakken, L.L., Sheridan, J \& Carnes, M. (2003) Gender differences among physician-scientists in self-assessed abilities to perform clinical research, Academic Medicine, 78, 12, pp.12811286.

Department of Health (2004) Hospital, Public Health Medicine and Community Health Services Medical and Dental Staff in England, 19932003, London: HMSO.

Holloway, I. \& Wheeler, S. (2000) Qualitative research for nurses (Japanese language edition), Tokyo, Igaku-Shoin Ltd.

Kilminster, S., Downes, J., Gough, B., MurdochEaton, D. \& Roberts, T. (2007) Women in medicine-is there a problem? A literature review of the changing gender composition, structures and occupational cultures in medicine. Medical Education, 41, 1, pp. 39-49.

Mason, M. (2010) Sample Size and Saturation in PhD Studies Using Qualitative Interviews. Forum Qualitative Sozialforschung / Forum: Qualitative Social Research. [Online], Available at:http://nbnresolving.de/urn:nbn:de:0114fqs 100 387 [Accessed June 12, 2012].

Nomura, K. \& Gohchi, K. (2012) Impact of genderbased career obstacles on the working status of women physicians in Japan, Social Sciences and Medicine, 75, 9, pp. 1612-1616.

Ohman, A. (2005) Qualitative methodology for rehabilitation research, Journal of Rehabilitation Medicine, 37, 5, pp. 273-280.

Reed, V. \& Buddeberg-Fischer, B. (2001) Career obstacles for women in medicine: an overview. Medical Education, 35, 2, pp. 139-147.

Takeda, Y. (2009) How concepts of life stage help your practice, Journal of the Japan Medical Association, 138, pp. 895-899. 